The literacy practices for assessment in the vocational curriculum - the case of Hospitality

\title{
Abstract
}

This article explores two case studies of the literacy practices of assessment in the vocational curriculum. Previous studies have identified learning in the vocational curriculum as being assessment-driven and atse-that subjects often associated with limited levels of literacy actually require multiple literacy practices from students. Drawing upon studies of the literacy practices of assessment in the teaching of hospitality the study explores the academic and occupational forms of reading and writing required of students. These literacy practices are often invisible to both students and staff and yet are central to the success of students in relation to attainment. The article suggests that vocational subjects may actually be more demanding in the range of literacies required for assessment than is often considered to be the case.

Keywords: Literacy; Vocational curriculum, Assessment, Literacies, Hospitality, New Literacy Studies 


\section{The literacy practices for assessment in the vocational curriculum - the case of Hospitality}

\section{Introduction}

While the focus of much policy debate around the globe is on the learning of literacy, in the last two decades there has been increasing research interest in the literacies necessary for learning (for example, Lee, 1996; Ivanic et al., 2009). The notion of academic literacies is now well established, particularly in relation to study in higher education (Lea and Street, 1998; Lea and Stierer; 2000, Lillis, 2001). The concept of curriculum literacies has also been developed in some studies (Wyatt-Smith and Cumming, 2003) to frame the reading and writing associated with learning particular subjects. However, much of this research interest has focused on the literacies associated with the learning of the more traditional academic subjects. There is a sense in which there has been a presumed view that the literacies associated with the learning of higher status academic subjects are the most challenging for students, and that lower status and vocational subjects require less complex reading and writing to be successful as a learner (Edwards and Miller, 2008).

This latter view was challenged by the Literacies for Learning in Further Education (LFLFE) project (Ivanic et al., 2007; 2009). The three year study of the literacies associated with learning across a range of subjects and levels in four colleges in Scotland and England indicated that the diversity of literacies associated with the study of lower level and vocational courses was greater than that associated with the study of more conventional academic subjects. This suggests that the literacies for learning for students on such courses may be more challenging than for those on higher level and academic courses. This is not 
simply because the students are conventionally 'less able', but because the challenges they face are greater in terms of the range of literacy practicesies required. These challenges correspond to the need to use a varietyeomplex set of literacy practices where aspects of those practices are multiple and more diverse in comparison to more traditional academic literacy practices. The LFLFE project proposed that a student on an academic route through the education system is scaffolded through a series of consistent messages as to what constitutes literacy; their literacy careers are focused on the development of extended forms of reading and writing associated with essayist culture. By contrast, students who follow a vocational route are expected to develop very diverse forms of literacy, both embracing aspects of essayist culture, but also the literacies related to the occupation or their subject. In other words, their literacy careers are far more diverse-and therefore demanding than those on an academic route (Edwards and Miller, 2008).

A further finding of the LFLFE project was that, while literacies for learning embrace a diverse range of purposes and practices, in colleges at that time, the emphasis was on literacies for assessment (Ivanic et al., 2009). In other words, as had been found by other researchers (for example, Torrance, et al., 2005), the curriculum was largely assessment driven and therefore it was the forms of reading and writing in relation to assessment that predominated. However, while assessment itself and the assessment of literacy areis a much researched areas-and also the assessment of literacy, there is to date limited attention to-the specific literacy practices necessary for assessment have to date received little attention. The focus of the project reported here is therefore on the literacies for assessment rather than the more conventional assessment of literacy. This article draws upon data from the Exploring Literacies in the Assessment Practices of Further Education project, which took place between 2010 and 2011 in Scotland. This project focused on the literacies associated with 
assessment in colleges and on vocational curriculum areas. In this study, we wished to focus on the area of student learning in which there were the most literacy practices i.e. assessment, and where there was most likely to be the greatest diversity of practice i.e. the vocational curriculum. The project researched two curriculum areas within one college in Scotland. This article focuses on one of the curriculum areas - Hospitality - and provides two case studies of the literacies for assessment within that subject. It builds upon a previous study of curriculum making in the subject of Hospitality (Edwards et al., 2009). It focuses on the range and diversity of literacy practices associated with the assessment of Hospitality courses and adds to the evidence that assumptions about the literacies required to study in the vocational curriculum need to be reassessed.

The article is in three parts. First, we focus on the theory and methods informing our study. In the second section we provide two case studies of the literacies for assessment in the teaching of two modules taught at different levels in Hospitality programmes in a Scottish college. Finally, we draw out inferences from this study in relation to the findings of the earlier study to suggest that, while often assumed to be limited in terms of literacy, the vocational subject of Hospitality is both diverse and multiple in the literacy expectations being placed upon students. However, these are often invisible to both students and staff.

\section{Theory and method}

The project was located in, and sought to extend theoretically, the notion of literacy practices developed in the well established area of New Literacy Studies (NLS). The latter examines the socially situated practices of literacy, embracing values, purposes, audiences, artefacts, etc. and the ways in which people negotiate their worlds drawing upon the resources available to them (Baynham, 1995; Barton and Hamilton, 1998; Barton et al., 2000). While people's involvement with texts is observable, their engagements are shaped by feelings, 
values, expectations and histories. An understanding of literacy therefore includes what is done with the text, who is involved with the text, how the text is engaged, and why the text is engaged in this way, leading to questions of power, value and authority. Work in NLS ew Literacy Studies-explores the diversity of literacy in which children, young people and adults engage (e.g. Barton and Hamilton, 1998; Hull and Schulz, 2002). Significant developments in digital literacies and the possibilities for new forms of representation through the combining of words and pictures have been charted as new technologies have become socially pervasive in many places (e.g. Cope and Kalantzis, 2000; Snyder, 2002; Kress, 2003). This work demonstrates the rich variety of literacy practices which are part of people's daily lives, but also reveals that these practices are not always visible within education provision. Lemke (1998) had earlier pointed to the diversity of literacy practices among students in post-school settings and their need to co-ordinate multiple literacies. The NLS framing of literacy practices as socially situated is contrasted with the autonomous model of functional literacy, which focuses on the individual's cognitive capacity and skills to use standardised forms of reading and writing.

The LfLFE project extended theoretically the notion of literacy practices, conceiving them as networks of micro-practices and artefacts, relationally enacted and stabilized into certain forms of reading and writing for particular purposes and contexts (Ivanic et al. 2009; Edwards et al., 2009). It identified nine aspects of a literacy practice that can be used both as an analytic framework and a pedagogic tool to establish what, why, who, how and under what conditions reading and writing is enacted (see Figure 1). This framework can be used to examine literacy practices at different levels of analysis, from the single event to an overall programme of study, and can provide a framework through which to explore how students do co-ordinate multiple literacies in the learning of a subject. In this article, the framework is 
utilised as an analytical tool through which to interpret the data at the level of the module researched, focussing on the literacy practices associated with assessment alone.

\section{Methods}

The project sought to address two research aims: to identify the assessment regimes enacted within the context of Scottish colleges; and to explore the meanings invested in assessment tasks by students and lecturers. Following previous NLS research, tThe methodology informing this project was broadly ethnographic in order to explore the student's values, attitudes and experiences, present and past, in relation to the literacy demands of assessment practices. The research took place in a college department which participated in The college was selected on the basis that the previous research for the -LfLFEiteracies for Learning in Further Education' project had been carried out in this site within the subject areas studied. This meant we had already developed research relationships with a number of the college staff involved in this follow-up project, which assisted in terms of access of informed eonsent.

\section{Provide details about the college}

\section{Explain why the choice of hospitality.}

Two modules were selected for study in Hospitality - the City \& Guilds Certificate in Culinary Skills and the Higher National Certificate in Professional Cookery (a higher level course). Provide details about the role of City \& Guilds. Documentary evidence in the form of course specification and unit descriptors produced by the Scottish Qualifications Authority and texts produced by college tutors and students in relation to the practices of assessment were collected.
Comment [s2]: Comment 1.2: not clear on the LfLFE framework and how it got us from the interviews to the findings.

Comment [s3]: What were the research questions for this project?

Formatted: Heading 2

Formatted: Left, Space After: 0 pt

Comment [s4]: Both reviewers: methods need to be better explained

\begin{tabular}{|l|}
\hline $\begin{array}{l}\text { Comment [s5]: 2.2: add details on the } \\
\text { college setting }\end{array}$ \\
\hline Formatted: Highlight \\
\hline Formatted: Highlight \\
\hline Formatted: Highlight \\
$\begin{array}{l}\text { Comment [s6]: 2.2: provide details on } \\
\text { hospitality - diverse in level and content } \\
\text { and it's place within the UK's highly } \\
\text { differentiated education system needs more } \\
\text { explanation }\end{array}$ \\
\hline Formatted: Highlight \\
\hline
\end{tabular}


Three cycles of in-depth interviews with staff and students and observations of class practices took place in spring 2010. In total, in-depth interviews were conducted with 11 students (six from the City \& Guilds Certificate, and five from the HNC), and two tutors - - . We conducted interviews and focus group discussions with staff and students on both courses, as well as undertaking observations of classes leading to assessment and the assessments themselves. It was necessary to explore the students' previous educational and work experiences and their trajectories into these courses to better understand how they engaged with the literacy demands of the assessment practices. The researeh for the 'Eiteraeies for Learning in Further Edueation' project had been earried out in this site within the subject areas studied. This meantwe hat already developed researeh relationships with a number of the college staff involved in this follow up project, which assisted in terms of aceess of informed consent. Two modules were selected for study in Hospitality the City \& Guilds Certificate in Culinary Skills and the Higher Nationat Certificate in Professional Cookery (a higher level course). Three cycles of in-depth

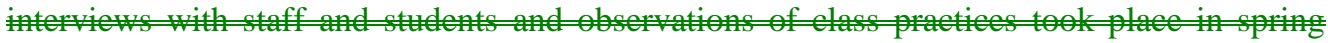
2010. In total, in depth interviews were conduted with 11 students (six from the City \& Guilds-Certificate, and five from the HNC). Two tutors were also interviewed. Initial focus groups were carried out with the participating students to explore their previous educational experiences and their reasons for studying the course. This enabled the researcher and the students to get to know each other and compare the different experiences and motivations for study. Observations of classes leading up to assessments and of the assessment themselves took place. Students and lecturers were interviewed before and after the assessments to explore the literacy practices involved in preparation for the assessments, those engaged in during the assessments and those involved in the evaluation of the practical sessions. Student participation in the project was on a random basis. Informed consent was gained from both 
staff and students on the basis that participation would not impact negatively or disrupt the existing practices of the course. Documentary evidence in the form of course specification and unit descriptors produced by the Scottish Qualifications Authority and texts produced by college tutors and students in relation to the practices of assessment was also collected. Informed consent was gained from both staff and students on the basis that participation would not impact negatively or disrupt the existing practices of the course. The lecturers and students were keen to engage in the research process as a means of reflecting on their teaching and learning through the assessment process and their associated literacy practices.

\section{The participants}

Formatted: Heading 2

Table 1 provides details about the students from the two courses who participated in the $\underline{\text { study. }}$

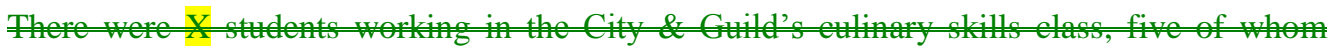
participat in the research. Three of the participants arked in the industry prior to andlor during the course, and two of them noted that this could mean some of the course was of little

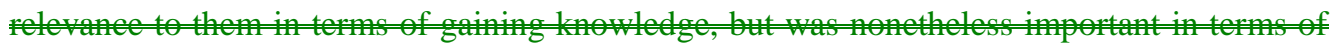
saining the qualification to be able to mon to the INC the following year. For example; Scott came to the Profescional Chef course having alrealy worked in kitchens, and as such

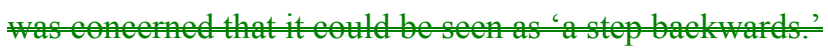

Table 1X: City \& Guild's pInformation on the participants in the studyarticipants.

\begin{tabular}{|l|l|l|l|l|l|}
\hline Name & Pseudonym & Gender & Age & Ethnicity & Educational/professional background \\
\hline City \& Guilds Culinary Skills & M & 29 & Scottish & Studied Highers and then worked in in Eng \\
\hline K & Colin & M & &
\end{tabular}




\begin{tabular}{|c|c|c|c|c|c|c|}
\hline & & & & & 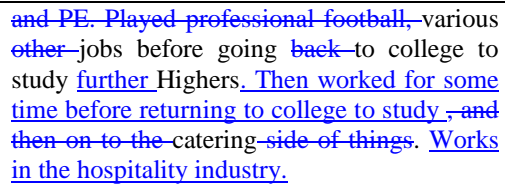 & \\
\hline \multirow[t]{2}{*}{$\mathrm{R}$} & John & $\mathrm{M}$ & c. 40 & Scottish & No prior experience of working in a kitchen & Formatted: Highlight \\
\hline & & & & & $\begin{array}{l}\text { but experience of working in unnamed } \\
\text { profession to level } 4 \text {. }\end{array}$ & 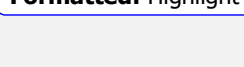 \\
\hline \multirow[t]{2}{*}{ M } & Brian & $\mathrm{M}$ & 17 & Scottish & Left S4 with some SGs. Dyslexic, sometimes & Formatted: Highlight \\
\hline & & & & & assisted by a scribe. & \\
\hline \multirow[t]{2}{*}{$\mathrm{D}$} & Scott & $\mathrm{M}$ & 21 & Scottish? & Started another HND then transferred to & Formatted: Highlight \\
\hline & & & & & $\begin{array}{l}\text { catering. Experience of working in kitchens. } \\
\text { Works in the hospitality industry. employed } \\
\text { in a local hotel working as a Chef de partie. }\end{array}$ & Formatted: Highlight \\
\hline \multirow[t]{2}{*}{$E$} & Charlie & $\mathrm{M}$ & 19 & Scottish? & Entered the course straight from school at the & Formatted: Highlight \\
\hline & & & & & end of S6. Works in the hospitality industryas & Formatted Table \\
\hline \multicolumn{6}{|c|}{ HNC Professional Cookery } & Formatted: Highlight \\
\hline \multirow[t]{2}{*}{$\mathrm{C}$} & Michael & $\mathrm{M}$ & $?$ & English & Attended Princes Trust catering course. & Formatted: Highlight \\
\hline & & & & & $\begin{array}{l}\text { Previously completed City \& } \text { Guilds } \\
\text { qualification. }\end{array}$ & \\
\hline \multirow[t]{2}{*}{$S$} & Sue & $\mathrm{F}$ & $?$ & South East & Previously studied in the US, and worked on & Formatted: Highlight \\
\hline & & & & Asian & $\begin{array}{l}\text { the continent in hospitalityin Spain as a sous } \\
\text { chef. Has aAlways worked in hospitality } \\
\text { cheffing. }\end{array}$ & \\
\hline \multirow[t]{2}{*}{$\mathrm{N}$} & Donald & $\mathrm{M}$ & $?$ & Scottish & Attended lLocal secondary school, then & Formatted: Highlight \\
\hline & & & & & $\begin{array}{l}\text { studied City \& Guilds qualification. On the } \\
\text { autistic spectrum and assisted by special } \\
\text { needs support. }\end{array}$ & \\
\hline \multirow[t]{2}{*}{ M } & Anja & $\mathrm{S}$ & $?$ & Polish & Previously completed City \& guilds & Formatted: Highlight \\
\hline & & & & & qualification part-time & \\
\hline
\end{tabular}

There were X students working in the City \& Guild's culinary skills class, five of whom participated in the research. Three of the participants worked in the industry prior to and/or during the course, and two of them noted that this could mean some of the course was of little relevance to them in terms of gaining knowledge. For example, Scott came to the Professional Chef course having already worked in kitchens, and as such was concerned that it might be seen as 'a step backwards', while Charlie said it could be 'a bit boring really'. However, most of the participating students were keen to progress to the HNC the following year, and as such it was considered important to gain the City \& Guilds qualification. but was nonetheless important in terms of gaining the qualification to be able to move on to the 
HNC the following year. For example, Scott came to the Professional Chef course having already worked in kitchens, and as such was concerned that it could be seen as 'a step backwards.'

Colin was attracted to the course because said he had 'always wanted to cook', but had delayed it because he didn't want to give up his job to go back to college. Likewise, Brian, who was dyslexic and supported with his learning issues in the college through a personal learning support plan, had always enjoyed cookery. John had no prior experience of working in a kitchen, and explained that he-was more interested in the management side of hospitality, hoping that the course would provide him with a way in to the 'sales side of the food sector'. not interested in becoming a chef. Instead, he was more interested in the management side of hospitality, and hoped that the course would provide him with a way in to the 'sales side of the food sector'. Two of the students entered the course straight from school; Brian from S4 having obtained some Standard Grades and Charlie having obtained Highers in S6. Like Scott, he had also worked in a kitchen prior to the course, and as such agreed that the course could be 'a bit boring really'. He also intended to go on to do the HNC the following year, before going 'straight inte the business'.

There were 11 students working in the HNC class. The Lecturer described them as a diverse group both in terms of ethnic origins and social backgrounds.

\begin{tabular}{|c|c|c|c|c|c|}
\hline Name & Pseudonym & Gender & Age & Ethnicity & Educational/professional background \\
\hline$E$ & Michael & M & $\underline{\underline{2}}$ & English & Previously completed City \& Guilds qualification. \\
\hline \multirow[t]{2}{*}{$\underline{\underline{S}}$} & Sue & $\underline{F}$ & $? \underline{?}$ & South East & Previously studied in the US, and worked in Spain as a \\
\hline & & & & Asian & sous chef. Always worked in hospitality cheffing. \\
\hline \multirow[t]{2}{*}{ N } & Donald & $\underline{\underline{M}}$ & $\stackrel{?}{\underline{\underline{?}}}$ & Scottish & Local secondary school, then City \& Guilds \\
\hline & & & & & $\begin{array}{l}\text { qualification. On the autistic spectrum and assisted by } \\
\text { special needs suppert. }\end{array}$ \\
\hline \multirow[t]{2}{*}{$\underline{\mathrm{M}}$} & Anja & $\underline{\mathrm{S}}$ & $\stackrel{?}{\underline{?}}$ & Polish & Previously completed City \& guilds qualification part- \\
\hline & & & & & time \\
\hline
\end{tabular}

\begin{tabular}{|l|}
\hline Formatted: Font: $9 \mathrm{pt}$ \\
\hline Formatted Table \\
\hline Formatted: Font: $9 \mathrm{pt}$ \\
\hline Formatted: Font: $9 \mathrm{pt}$ \\
\hline Formatted: Font: $9 \mathrm{pt}$ \\
\hline
\end{tabular}


Of the 11 students working in the HNC class four took part in the research. The lecturer described the class as a diverse group both in terms of ethnic origins and social backgrounds.

Three of the four participants students-studied the City and Guilds culinary skills qualification prior to joining the HNC. Like the students on the City \& Guilds course, the $\underline{\text { HNC The-students had various reasons for studying the HNC, but all were passionate about }}$ cooking. Michael, who had been brought up in care, wanted to counsel young people in social services through teaching them how to aboutcooking and looking after themselves. Sue saw the qualification as a passport to getting a better job, possibly and hoped it would help her to get a job-as an executive chef for a big food production company. She had worked as a chef in a number of international locations, and enjoysed the creativity of cooking, but found the organisation of the course made it difficult to juggle work and family commitments. Donald initially wanted to go to university but since studying the HNC had identified various career $\underline{\text { trajectories in the industry, and was considering going to a culinary school in the states to do }}$ $\underline{\text { some specialist training to become a head chef in a Michelin stared restaurant. Anja studied }}$ the City \& Guild's qualification part time so as to allow her more time for working in the industry. She intended to continue on to do the HND Hospitality, and then a degree in Hospitality management.

\section{Analysis}

(Figure 1 near here)

The analysis phase synthesised the data identifying differentiating factors within the literacy for assessment practices. It drew upon transcribed interviews and focus groups and observation notes of classroom practices as a basis for triangulation. Initially ${ }_{2}$ descriptive case studies were written which incorporated pen portraits of the participating students, background information about the modules, and detailed write-ups of the literacies involved 
in the assessment practices. Cross case thematic analysis was then undertaken to identify categories of assessment practices. From this analytical process three broad literacy practices associated with assessment were identified. These are:

1. Literacies for preparing for assessment e.g. making sense, planning work, drafting, revising

2. Literacies for doing practical or project based assessments e.g. supporting practical work, simulated work tasks

3. Literacies for evidencing learning e.g. providing evidence, demonstrating understanding, evaluating performance.

Literacies for preparing for assessment relates to how students prepared for the written assignment, and how they went about completing their written work more widely. Literacies for supporting the three practical assessments, such as writing menus, checking costs and order lines, and preparing dishes for the practical assessments were a key part of the category of literacies for doing practical or project based assessments. Literacies for evidencing learning were present in the ways in which students provided evidence and demonstrated their understanding through the written assignment proforma and portfolios. This was also evident in how students evaluated their performance in the practical assignments. These three types of literacies were not always distinct, and there was some overlap, particularly between literacies for doing practical assessment and those used for evidencing learning. In all three literacy categories, students queried the relevance and usefulness of the assessment tasks to their future or indeed current employment in the occupation.

The analytical framework developed through the LfLFE project was then used and further developed as a theoretical lens by which to analyse the aspects of the literacy practices for assessment identified in the transcripts. We interrogated the data drawing upon the aspects of 
a literacy practice framework to both interpret the data and also to test the validity of the framework as a heuristic tool. The case studies presented below therefore reflect the outcome of a three stage analysis - descriptive, thematic and theoretical.

\section{The cases of Hospitality}

\section{Case study 1: Culinary Skills}

This first case is based on the City \& Guilds Certificate in Culinary Skills. This unit is part of the Professional Chef Award City \& Guilds. There are four main assessments for this certificate: one written multiple choice assignment, and three practical assignments with written elements. Some of the students on the course will progress to the HNC in Professional Cookery (the second case study) or Hospitality, while others prefer to go straight into industry. At one level, it might seem there is very limited literacy associated with the assessment of this lower level vocational course. However, the data suggests otherwise.

\section{Literacies for preparing for assessment}

Literacies for preparing for assessment were most evident in relation to students' preparations for the multiple choice written assignment; the final assessment in the award. Students had different ways of revising for the written paper. Much of the preparation for the written assignment took place in their own time, and in locations outside of college; often at home or in the library. Students used a range of actions and different sources, when revising for the paper, including textbooks and lecture handouts; - Aa sas one student said, 'it's all [the information needed to pass] in them books'. Some also said they mentioned-referreding to their own catering and cookery books to which they referred. 
Writing processes included writing notes, both during lectures and after. However, some students spoke of the difficulty they had in writing notes, and highlighted the importance of listening processes in preparing for the assessment. Brian, who was dyslexic, One student struggled to remember what the lecturer had said, and said he 'gave up' keeping notes, preferring instead to listen in class and then try and write up notes when he got home, using handouts.- $\mathrm{He}_{\mathrm{H}}$ Another studentsaid he found taking notes particularly difficult and blamed his 'pretty bad' reading and 'rubbish' handwriting for his dislike of paperwork; -'as long as I can hear it I don't need to write it down' he said. He was assisted in taking notes by a scribe, but said he tould-sometimes tookakes notes himself so that 'it looks like I'm actually doing some work instead of just sitting there'.

Students' identities and values came through in interviews with regards to the different literacies. John, aA mature student, spoke of how he found the revision process difficult. This was in contrast to some of his fellow students:

Because I did one thing that a lot of them didn't do, and a lot of them have not passed. It's 'cos I studied, I went home and put effort in, you know, I've never studied in my life. In contrast to his peers who used computers at school Johnhe said he was 'hopeless at the computer' and had to teach himself, for example, using Google to learn how to use Excel, whilst also being shown shortcuts in Word by the lecturer, in order to copy and paste. He said that there should be 'no excuses' for not passing the paper, as 'we've all got books, right, and we can go to the library'. He described some of the actions and processes he went through when revising for the written paper, f. For instance, finding a book on nutrition; and 'so I helped myself reading that', he said. He sometimes took notes because 'I usually find if you take notes you remember things 'cos you've written it down, but usually I read a day before I 
get my exam'. John This student had also read about exam technique when he had done a previous course on finance.

Ivanic et al. (2009) refer to the increased use of 'intermediate documentation' by colleges in order to help students pass assessments. In this instance, the college provided students with 'prelim tests' based on the content of the course. Doing these shorter formative assessments was seen by the students as being particularly useful in terms of passing the test, and allowed them to see where they had gone wrong.

\section{Literacies for doing practical or project based assessments}

The three practical assignments for this course also included significant written elements. Formatted: Normal Here, literacies related to both supporting practical work and simulating work tasks. All three assignments weare similarly structured as students weare given their assignments (i.e. what they have to cook and who for) two to four weeks prior to the day of the practical. The written part of the assignment takes took the form of a workbook containing various documents which must had to be handed in prior to the practical. On the day of the practical students weare assessed on the taste, flavouring, technique etc of their dish, its appearance and the written planning aspects of the assignment.

Assignment 3 wais assessed by an External Verifier (EV) from The City and Guilds, who is was not involved in the teaching of the course. Both tThe lecturer said that this gave the students something to aim for when they knew it is an external person doing the assessment; 'it keeps them on their toes', and 'applies a little healthy pressure'. The EV and the lecturer Comment [s11]: Omit to cut words? emphasised the practical, industry-led nature of the course. The EV explained how the Certificate is a straightforward qualification "that cuts to the chase with none of the difficult language involved in the SQA (Scottish Qualifications Authority) qualifications'. He found the literacies involved in the qualification to be less academic than in other subject areas 
because of the fast changing pace of the industry where fashions and styles were always changing and where training and qualifications needed to be to the point and practical for an industry-led vocation. The purpose of the course according to the lecturer was also that it should give students 'a realistic experience' and 'teach them what they'll be doing in the industry.'

Given this emphasis on the vocational nature of the award, it is therefore surprising to see just how much written work students were expected to produce as part of the practical assignments-therefore. They required the $\underline{S}$ students were required to take on the role of professional chef, and produce satisfactory dishes for the intended audiences of both lecturer/EV and a fictional paying customer. Alongside preparing their finished dishes, students were-required-had to complete a workbook/booklet which contained the written aspects of the assessment. The genre of the workbook meant that students had to conform to certain constraints, and were required to complete the various sections while paying attention to particular conventions. For example, students were asked to write their menu, describe their recipes and to provide references. While students were able to articulate their recipe sources in observed discussions, the extent to which they actually referenced their recipes in the booklets was variable.

Students also had to complete a proforma detailing their plan of work in the workboeks. $\underline{\text { Scott }}$ This was-describedseen this more as 'writing down a sequence rather than a time plan'. However, as such he it was-deemed it 'useful' because ;of by a student, 'in-the way that you think of the process, the way things should be done, so it's in your head what should be done first.' While the proforma included a template to be completed, laid out how it was intended this should be done, most of the students actually produced their own planning documents which were considered more practical for the sort of working practices they needed to do in 
the kitchen. This meant that students were often writing and using doing two alternative plans, one to pass the assessment which adhered to the conventions and constraints as laid down in the workbook, and another which they actually used to support them while cooking. In interview, Colin a student explained that his task was to 'write it all in the book', but that 'I don't really look at the time plan 'cos I know what I'm needing to do anyway'. He said he wrote the time_plan in the assignment booklet "just for the purposes of like handing it in to get the marks for it', and instead created his own kind of plan which was more like a graph or 'a timeline for each thing' which allowed him to mark off each item as he did them. Some of the s Students were also observed also-adaptinged the standardised work plans to something which was considered more effective for use useable in the actual kitchen. The process of reading in this case was non-linear, with the student referring to the time_plan on and off as they went about their cooking. A number of students thought that the planning, reading and writing they did was useful in terms of working out what they had to do, but remarked on the need to be flexible and change things as they went along. Students reported They did not think that the reading and writing they did for the planning was very unrealistic in terms of what they actually had to do on the job.

\section{Literacies for evidencing learning}

Literacies for evidencing learning were most prevalent in some of the written aspects of the practical assignments. These-written sections of the practical assignments were largely descriptive; f.For example, students had to describe the colour/texture/flavour of their dishes, the skills required to make it and the methods used in the cooking. However, the conventions of the proforma were nonetheless unclear to a student, Brian, who expressed confusion at was nonetheless 'confused' by the language used, and was unnot being-clear of-what was being
Comment [s12]: Reviewer comment 2.5: acute finding which might be more fully developed, with examples of contrasting literacies involved, not just how their purposes are perceived. 
asked of himthem in to-providinge descriptions of colour, texture and flavour of histheir dish.

The conventions of the proforma were unclear to him.,

Students used different modes and technologies to complete the written aspects of their assignments, including both pen and paper and computers. Brian One student-said he did most of his writing assessments on the computer; as 'at least the lecturers can actually read it', and 'I'm a wee bit faster on the computer than I am writing it out', he said. John Another used the computer forto prepare his communications assessments, but chose to complete did the written parts of his practical assignments with pen and paper. Different sources were used by students in relation to literacies for evidencing learning, including . Students used-text books, recipe books and the internet for this task. For some students using computers to find and read lots of information on screen held negative connotations because of its similarity to how they had had to work in school.

The final written assessment followed the styles and conventions of an academic exam lasting 1.5 hours, using the genre of multiple choice questions, which covereding all aspects of the course from throughout the year. The students were then subject to a number of exam constraints in terms of their participation with others (they had to work alone) and the requirement to complete the paper in a set period of time. The purpose of the written assignment was for students to demonstrate their knowledge and understanding of the course. The assessment was perceived by sStudents saw the assessment-as something they had to do in order to as a means of either progressing onto the HNC or using the qualification-to continue on-working in the industry.

While some questions were described by students as 'pretty common sense' (Charlie), other topics covered by the written paper used quite technical language, requiring students to use 
terms they would not normally associate with working in the kitchen. For example, Briana student contrasted the terms 'biodeficient' and 'bacteria reproduction' with 'dirty'. Some students said that they found it harder, and 'struggled' to remember the more technical topics covered by the written paper, for example, questions relating to nutrition and vitamins-.

To me, you have to learn it more, you have to look at it more, but I just can't be bothered to be honest, but I'll have to.ae. I will do it for, like, the final exam because I want to do really well in the final exam. (John)

As John As one-said, 'a lot of the stuff is just for exam purposes really', and another saidand, 'it's just useful in the terms of doing the exam to get the marks; $;$; it's stuff you might not think about'. Ultimately, he said, 'I'd rather learn in a real environment rather than sit in a classroom... to be honest'.

While it wasstudents acknowledged that some of the information asked in the paper was quite complex, and that there was much to learn, the genre of the multiple choice paper was seen as making the task more manageable. A student said:

It was ok 'cos that's all kind of multiple choice. You don't have to do a lot of writing for that, do you? You just have to know the right answers. (Brian)

To summarise then, at the City \& Guild's At this-level, the literacies involved in the assessment of the students' work are very broad ranging, incorporating multiple purposes, evidencing learning and the more practical aspects of getting the job done. The identities, roles and values that the students bring to the course are also varied; these complex processes of identification are contingent on how the assessments are enacted as the course progresses. The range of texts involving different modes, types of collaborations and different sorts of constraints and conventions presents a complex literacy landscape through which the students needed to navigate and negotiate their way.

Comment [s15]: Reviewer: what do we mean by complex? More explanation needed 


\section{Case study 2: Professional Cookery}

The second case study is of the Higher National Certificate (HNC) in Professional Cookery which is the equivalent of first year university study in Scotland. The research on this course focused on the production cookery units:-; Cold Kitchen, Hot Kitchen, Sweets and Deserts. In practice, it was impossible to isolate just one unit, or even these three from the others, as they were taught holistically through practical work in the kitchen and theory work in the classroom. The HNC specification places emphasis on assessing the whole outcome or combinations of outcomes rather than individual performance criteria. The graded unit consists of a portfolio that draws together all the units, both theory and practical, through a wide range of different sorts of texts._The HNC is made up of 50\% practical and $50 \%$ theoretical/written aspects. The lecturer said students' assessment was on-going and consisted of assessing them while doing a service in the kitchen, under the pressure of a real working environment. As well as on-going assessments, students also completed a portfolio of their work.

\section{Literacies for preparing for assessment}

Literacies used for preparing for assessment, for example, preparing for tests, revising, etc were less frequently referred to in the HNC than in the City \& Guilds award. This is mainly due to the emphasis in the $\mathrm{HNC}$ on literacies for doing practical work and evidencing learning. Despite this, students did talk about how they prepared for assessments.

Students referred to examples of how they had collaborated with their peers as a means of making sense of some of the more theory-based work. They spoke of using different sSources of information used whento reviseing for regular tests and exams, includinged Power-Points, handouts and booklets supplied by the lecturers. DStudents used different processes, familiar from other educational and work contexts, were used, such as scanning, note-taking and 
highlighting, when reading and writing from this material. Michael One student-said that the students worked together as a group and explained that "what we do is we learn everything through the Power Point, and then we break everything down ourselves into what's relevant, 'cos I mean there's stuff in there that's not relevant' to what they considered necessary to know for the assessmentwould be doing.

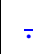

As with the City \& Guilds course and academic literacy practices more broadly, mock assessment practice-papers were also used specifically for revision as a way for students to identify which aspects of the course they should concentrate on. For some-students, the purposes of preparing for assessment were to read and learn enough with which to pass the test, concentrating on the key information required.

Tthe practice test shows you, points you, in the directions of the areas that it's going to look at. S, so then what you do is you look at those sections, you highlight those ones, and they're the ones that you focus mainly on. (Michael)

\section{Literacies for doing practical or project-based assessments}

The main practical assessment that covered the learning outcomes for the three units consisted of a simulated work task in which the students planned, executed and evaluated the supervision of the kitchen for a restaurant sitting. This task is simulated only because the students are not actually employed, but they are cooking for real customers in a real restaurant within the college. This assessment focused on one day in the kitchen when

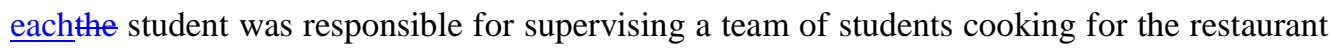
for a lunchtime sitting of up to 40 people. The diners were a mix of staff at the college and members of the general public and some students. The assessment task was distributed over a 
considerable amount of time (in some cases the whole semester) and various spaces (the kitchen, the classroom, the computer rooms, the home, the coffee area etc). The students took it in turns to supervise the restaurant once a week for this assessment task.

The kitchen sessions were used to cover the practical side of the production cookery units and were often part of the preparation for the restaurant service. Various assessment tasks were carried out in this integrated manner as part of the work needed to be done for the restaurant. There was a big focus on team work throughout this course and across course groups. HNC students worked closely with the Higher National Diploma (HND, equivalent to the second year of university in Scotland) hospitality management group and the National certificate (NC, non--higher education) hospitality group, taking turns to supervise and be supervised. Students took on various roles; at times they would be supervised by the HND students and at times they would supervise the work of the NC group. The lecturers also worked closely with each other and as part of the teams in the kitchen, and similarly. At times, the lecturer-took on various different roles. As well as their more formal role of lecturer when it came to assessing the students work and giving feedback, they also moved between the roles the role of head chef, and working, at other times they would-simply as be-another member of the kitchen team. They took the more formal role of lecturer when it came to assessing the students work and giving feedback.

Writing menus was a key part of literacies to support practical work and simulated work. Menus were designed, often in collaboration with other students, taking into account cost, Comment [s16]: Reviewer comment 2.5: more details wanted on different menus for different audiences and the paperwork associated with assessment. seasonality of produce and various options for customers, including vegetarian. Menus generally conformed to certain conventions associated with the genre, and students spoke of trying to 'enhance' the dishes by giving them appealing names. Menus were developed from reading and viewing a range of different sources, including recipe books, the internet, and, as 
Michael one student said, 'common knowledge'. Students wrote the menus with a number of different audiences in mind - the paying customer, the lecturer who would assess the dish, the fellow students who had to use the menu to prepare the dish in the kitchen, and the external examiner who would assess the final portfolio.

There was a considerable amount of paperwork generated through the planning process. Observations of the assessment of students who were supervising the kitchen drew attention to the rich array of texts that were integral to the process of getting the job done. Some of these texts were part of the formal assessment and others were simply a way of organising the work. However, a large proportion of these texts were actually kept and put in the portfolio which was submitted as integral documents in the graded unit. For instance, $\underline{\text { Sueene student, }}$ who was responsible for the service on the day of the observation, had a range of texts that she had prepared especially for the her assessment and for the purpose of helping to make the day run smoothly. These were read in a non-linear way, picked up and put down as they were Formatted: Font: Not Bold needed. She had her own hand drawn and coloured--in pictures of each dish, while. The individual recipes for each dish and its various components were on printed sheets of paper. She had also designed and produced her own staff and customer feedback forms which she had designed and produced herself-using a on the-computer. Both written and drawn modes of communication were in use here, as were different technologies, with both pen and paper and computers being used. She had her own activities list and an overall work plan that encompassed timings, activities, and points to remember which was arranged on a form in three columns.

While Sue This student, who was-superviseding the other_students in the kitchen, she , delegated the responsibility for health and safety to a fellow student who was tasked with completing the necessary paperwork. This consisted of a proformawas a form with a number 
of different sections which covered, and - a variety of different topics includingeovered: personal hygiene control, monitoring control of food contamination and a cooking temperature monitoring form. An additional There was alse a-proforma related to form with details about the student responsible for various cleaning tasks, the frequency with which $\underline{\text { these }}$ tasks were performed, and the materials, chemicals and the methods used. Theis student circulated around the kitchen checking on all aspects of health and hygiene and filling in the form as he went, observing . He observed the team's practices and takinge日k notes in the relevant parts of the form. He was also respensible for checking cooking temperatures. The process of reading and writing in this task was non-linear wherebywith the sheets were completed and carried out intermittently throughout the kitchen session.

\section{Literacies for evidencing learning}

While literacies for supporting practical and simulated work tasks made up a significant part of the course, these often overlapped with literacies for evidencing learning, as the literacies which supported practical work were ultimately assessed in the form of the student's portfolio. This is sent to the SQA, and records in which details of the preparation techniques, , cookery processes, and presentation of the dishes produced-and presentation of dishes have to be recorded. This is sent to the SQA. In the unit specifications, there are various guidelines relating to assessment and the types of texts that are involved. The guidelines also recommend that students are encouraged to use a multimodal approach to providing evidence in their portfolios, using photographs and drawings to show how finished dishes arend presentedation of dishes. In contrast to the City \& Guilds award, there is a greater emphasis on academic language and conventions in the HNC. The guidelines state that the portfolio should be supplemented with further written and photographic material demonstrating this critical approach'. 
Students had to complete and collate an array of different forms and documents, including those pertaining to the choice of dishes and ingredients, presentation, self-evaluation forms, questionnaires, feedback from customers etc. As well as this, they had to include documents more directly related to supporting practical work, such as time plans, cost sheets and those related to training and supervision required as evidence of learning. While other aspects of the course involved working with other students, the emphasis in literacies to provide evidence of learning was upon working alone.

There were areas in which students were able to express their own individuality, particularly in terms of the presentation of pertfolios. One of the students painted in her spare time and her 'artistic flair' came through in the way she designed and personalised her portfolio, particularly in her coloured drawings of her dishes. Observations also noted students' use of computers to design different fonts to ensure the folio was well presented.

Comment [s19]: Omit to cut words? have moved some of this below

The folio represents the culmination of work covered throughout the course. Considerable time was spent on budgeting and sourcing ef-ingredients, training ef-staff, and other wider duties over and above the actual cooking aspects of being a chef. The classroom sessions were used for providing evidence and the more academic type of literacies where the students filled in their log books under the guidance of their tutor. It took time and effort to prepare

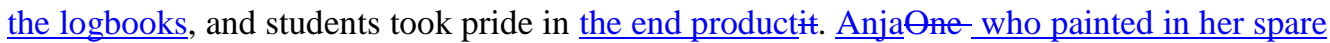
$\underline{\text { time, and whose 'artistic flair' came through in the way she designed and personalised her }}$ portfolio for assessment, spoke of the 'intense' process-of preparing their pertfelies for assessment, and said 'you just kind of feel like you achieve something'. Another student spoke of the sense of achievement gained from having something to show for all their work on the course, and they speke-of being able to use it to show future employers, which provided gives itan added sense of purpose. 
Self-evaluation made up a considerable part of the HNC. The evaluation tasks asked students to write extensively on their own performance and what they would do differently in future. This process was quite complex. The students received both written and verbal feedback on their work, from their lecturers and the customers, whilst at the same time they had as well as having to reflect upon and assess their own workthemselves and provide self assessment. The lecturer was of the opinion that the written evaluation tasks were not very authentic, as this would not happen in the industry, but would instead take the form of an informal chat at the end of service.

The evaluation aspects of the course are rather too much for some of the students that struggle with the extended writing. Some of them do fine ${ }_{2}$ but those that are more focused on the practical cooking really struggle with this aspect and it can bring their grades down.

Another example of a task involving paperwork which would be unlikely to be necessary when in employment is the training planning exercise, which assessed how well students trained their peers. Students were given a scenario and had two weeks to write a 500 word essay describing what they would do if there was a problem in the workplace when managing a team. They were unable to collaborate with other students for this task, despite completing it in the classroem with other students present.

All the texts discussed in this section were produced by the students for the ultimate purpose of recording and providing evidence for assessment, and also, in some cases, to support practical work and simulated work tasks. However, the students agreed with the lecturer that some of the planning and evaluation activities that they had to engage in for assessment purposes were over and above those that were practically needed to get the job done. While students acknowledged that their work did not exactly mirror that of the industry, for some 
this did not negate the benefits that they gained from working in this way. Sue, who already had extensive experience of working in the industry, said this allowed her to see the usefulness of doing in-depth research into the different commodities and how to source them:

I think it's very good to open your mind; to expand your knowledge; to know where to

look for; what to look for; and what you have to consider when you open your own business... every small, little detail - there are a lot of things. [...] but you don't really think about it until you go into the industry. It's a whole process you've been doing. It's all come together and you realise 'oh, that's really important'. But when you do it separately you kind of get lost; you don't see what that's for. (Sue)

Reviewer comment 1.1: how/why do the diverse/inauthentic literacy practices mean that it is more complex/challenging? Suggests that a step in the argument is missing.

\section{Inferences}

At the start of this article, we made reference to how lower level qualifications and those associated with the vocational curriculum are often perceived to be limited in terms of their literacy demands. The former has been challenged by work done by researchers such as Lemke (1998) and Ivanic, et al. (2009). Given that the LFLFE project, like others (Torrance, et al., 2005), had identified the curriculum in colleges as being assessment driven, this project focused on the literacies of assessment to establish the nature and extent of literacy practices in which students participate in the study of two Hospitality modules.

The research on the hospitality units at both levels demonstrates that there is a large and complex amount of reading and writing involved in the assessments for these qualifications. The demands on the students are significant as they learn to develop the literacy practices needed for the industry, those needed for educational progression and those needed to pass 
the assessments. Both qualifications have a large overlap between the literacies for doing the job, preparing for assessments and those needed to provide evidence of learning. Large amounts of the literacy practices are embedded in doing the practical tasks of the courses. However, the students and the lecturers were critical of some of the literacy demands from the point of view of them not being needed in the industry. While much of the writing for the students on the courses did not conform to the traditional essayist culture, students were required to co-ordinate a range of genres and semiotic modes in order to submit their work for assessment. Unsurprisingly perhaps, this took a slightly more traditional academic form in the higher level course, as evidenced by the need to provide references and rationales in written work.

This article has also set out to evaluate how well the theoretical framework, developed within the LFLFE project, works in providing a heuristic model through which to develop more analytically framed case studies of literacy practices. The case studies above provide evidence that such a framework can be useful in identifying the different aspects of literacy practices at play in dynamic curriculum settings. However, it is also the case that this form of analysis has led to the aspects being taken as separate elements in the overall assessment practices of the courses rather than providing a basis upon which to examine the micropractices through which it was argued literacy practices were assembled. In relation to the former, the framework provides a useful structuring through which to analyse diverse datasets and identify the range of aspects that shape the enactment of literacy practices for assessment. In relation to the latter, the analytical work would need to take another focus to test it out more fully. A focus on the networks and assemblages of particular aspects of literacy practices for assessment would be usefully employed to develop assessment practices for particular purposes, but this is another article. 
Overall, this study of assessment adds to the evidence that the vocational curriculum and lower level qualifications do entail extensive and diverse literacy practices on the part of lecturers and students. It opens up further the need for additional studies of different contexts and curriculum areas to enhance better our understanding of literacies for learning, as the possibilities for reading and writing expand.

Note: This research was funded by the Economic and Social Research Council (RES-000-223315). Our thanks to the the participants in the project and to the reviewers of this article.

\section{References}

Barton, D. and Hamilton, M. 1998. Local literacies: Reading and writing in one community. London: Routledge.

Barton, D., Hamilton, M. and Ivaničě, R. (eds) 2000. Situated literacies: Reading and writing in context. London: Routledge.

Baynham, M. 1995. Literacy practices: Investigating literacy in social contexts. London: Longman.

Cope, B. and Kalantzis, M. (eds) 2000. Multiliteracies. London: Routledge.

Edwards, R. and Miller, K. 2008. Academic drift in vocational qualifications. Journal of Vocational Education \& Training 60, no. 2: 123-131.

Edwards, R., Ivanic, R. and Mannion, G. 2009. The scrumpled geography of literacy. Discourse 30, no. 4: 483-500. 
Edwards, R., Miller, K. and Priestley, M. 2009. Curriculum making in school and college: the case of hospitality. The Curriculum Journal 20, no. 1: 27-42.

Hull, G. and Schultz, K. (eds) 2002. School's out: bridging out-of-school literacies with classroom practice. New York: Teachers College Press.

Ivanic, R., Edwards, R., Satchwell, C. and Smith, J. 2007. Possibilities for pedagogy in further education: harnessing the abundance of literacy. British Educational Research Journal 33, no 5: 703-21.

Ivanic, R., Edwards, R., Barton, D., Martin-Jones, M., Fowler, Z., Hughes, B., Mannion, G., Miller, K., Satchwell, C. and Smith, J. 2009. Improving learning in college: Rethinking literacies across the curriculum. London: Routledge.

Kress, G. 2003. Literacy in the new media age. London: Routledge.

Lea, M. and Stierer, B. (eds) 2000. Student writers in higher education: New contexts. Buckingham: SRHE/OUP.

Lea, M. and Street, B. 1998. Student writing in higher education: an academic literacies aproach. Studies in Higher Education 11, no. 3: 182-199.

Lee, A. 1996. Gender, literacy, curriculum,: Rewriting school geography. London: Taylor \& Francis.

Lemke, J. 1998. Multimedia literacy demands of the scientific curriculum. Linguistics and Education 10, no. 3: 247-71.

Lillis, T. 2001. Student writing: Access, regulation, desire. London: Routledge.

Snyder, I (ed) 2002. Silicon literacies. London: Routledge. 
Torrance, H., Colley, H., Garratt, D., Jarvis, J., Piper, H., Ecclestone, K. and James, D. 2005. The impact of different modes of assessment on achievement and progress in the learning and skills sector. London: LSDA.

Wyatt-Smith, C. and Cumming, J. 2003. Curriculum literacies: expanding domains of assessment. Assessment in Education 10, no. 1: 47-59. 